\title{
DESIGN OF DOUBLE-EGG CURVE IN THE LINK ROADS OF TRANSPORTATION NETWORKS
}

\author{
İbrahim Koç, Kutalmış Gümüş, Mahmut Ŏğuz Selbesoğlu
}

Original scientific paper The turns from highways to settlement areas are achieved by link roads. For the safety of these turns, turning radii are required to be large. However, it is not always possible to achieve these turnings by means of arcs of circle with large radius, as different factors, such as topography, the state of settlement, problems impossible to overcome and economic conditions, do not allow designing such a route. Instead, for the sake of traffic, linear variation of the line curvature or maintaining the line curvature at constant value is highly desirable. One of the line geometries is the clothoid egg curve. Single and double type clothoid egg curves are used in many applications. In this study, the calculation and design of double-egg curve are explained by equations and figures in detail. For the design of two egg curves used in rotation from main road to connecting road in transportation networks as application, an example is provided for a better understanding of the subject. The main points of rotation geometry with the coordinates of auxiliary points and other intermediate results are given in a table. The main purpose of this study, the theory and calculations of two egg curves will provide basis to practitioners on a sample in a detailed way. By the fulfilment of design and its calculation of this rotation geometry which provides safer and more comfortable driving, it is hoped to be useful for practitioners.

Keywords: clothoid; curvature; double-egg curve; egg curve; length of transition curve

Projekt dvostrukog kružnog zavoja na prilaznim putevima prometnih mreža

Izvorni znanstveni članak

Skretanja s glavnih cesta do naselja postižu se prilaznim putevima. Zbog sigurnosti ovih skretanja, zakretni polumjeri trebaju biti veliki. Međutim, nije uvijek moguće napraviti ova skretanja kružnim lukovima velikog polumjera, budući da različiti čimbenici, kao što su topografija, položaj naselja, problemi koje je nemoguće prevladati te ekonomski uvjeti, ne dopuštaju izradu takve trase. Umjesto toga je, zbog prometa, poželjna linearna varijacija zakrivljenosti linije ili održavanje konstantne vrijednosti zakrivljenosti linije. Takva je klotoidna krivina jajeta. U mnogim se aplikacijama primjenjuje jednostruki ili dvostruki tip takvih klotoidnih zavoja. U ovom se radu proračun i projektiranje dvostruko kružnih zavoja detaljno objašnjavaju jednadžbama i slikama. Primjer projekta dvostruko kružnog zavoja primijenjen u skretanjima s glavne ceste u prometnim mrežama daje se zbog boljeg razumijevanja samog predmeta. U tabeli su prikazane glavne točke geometrije rotacije s koordinatama pomoćnih točaka. Nadamo se da će osnovna svrha ove analize, teorija i detaljni proračuni dvostruko kružnog zavoja i njihova primjena kojom se omogućuje sigurnija i udobnija vožnja, biti od koristi praktičarima.

Ključne riječi: dužina prijelaznog zavoja; dvostruki kružni zavoj; klotoid; kružni zavoj; zakrivljenost

\section{Introduction}

In transportation networks, two-way traffic between main roads and settlement units is attained by link roads. For the sake of safety, the turns in these link roads are required to be performed by means of circular curves with large radius. However, this is not always possible as different factors, such as topography, the state of settlement, problems impossible to overcome and economic conditions, do not allow designing such a route. Instead, if linear variation of the curvature along the turn or maintaining the curvature at constant value is attained, then the restrictions mentioned above are eliminated. Simultaneously, the effect of centrifugal force could be minimized. By this way, the turn becomes safer. One of the line geometries ideally complying with this proposal is the clothoid egg curve. In different studies, i.e. $[1 \div 8$, $16,17]$, the quantities and parameters used in the calculation of egg curves have been explained. Egg curves, single or double, are used in many applications, e.g. as link roads for highways, in arrangement of urban junctions and playfields etc. [2, 5, 8]. There are 8 main points and 7 pieces of axis in the double-egg curve explained in this study. Two of these pieces of axis are clothoid, three are arcs of circle and two are pieces of clothoid, i.e. egg curve. The curvature of these segments changes linearly or partially keeps constant without sudden variations to minimize the effect of centrifugal forces (Fig. $1 \mathrm{a}, \mathrm{b}, \mathrm{c}$ ). a)

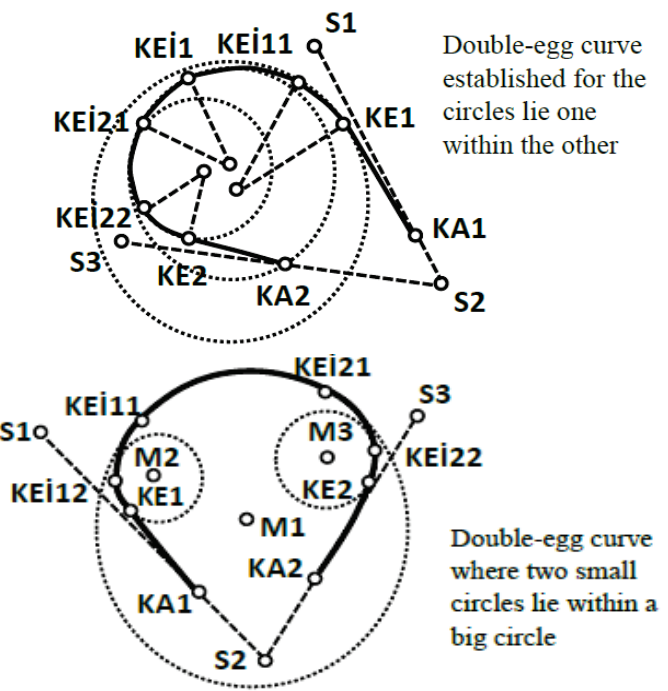

c)

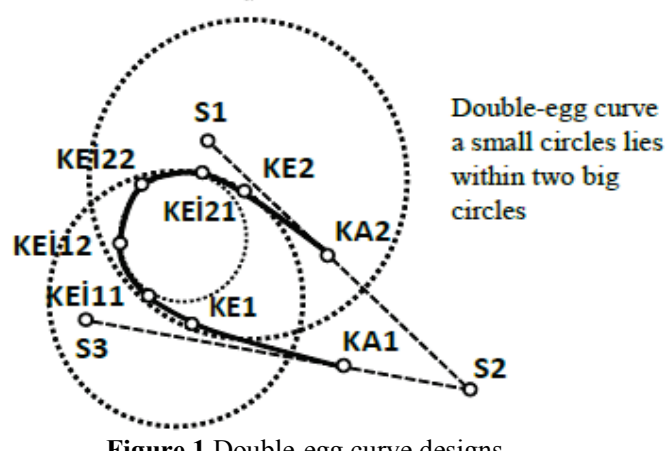

Figure 1 Double-egg curve designs 
The purpose of this study is to demonstrate the calculation and design of double-egg curve by equations and figures in detail, especially for the applicability of the curve in the transportation networks. In order to help the users, design of a double-egg curve sample on a turn to a link road was made. Main points of the turning geometry, coordinates of the auxiliary points and other intermediate results are tabulated to check the results. The link roads established in this way allow more reliable and comfortable transportation.

\section{Materials and methods \\ 2.1 Double egg curves and their designs}

Single and double egg curves consist of clothoid and circular arcs. Ref. [6] presents related examples and applications of them. In this study, information regarding the types of double egg curves and explanations about the solutions has been given but numerical applications are excluded. Also, [9] conducted a study related to a single egg curve. Besides, literature contains parabolic, bloss, co-sinusoidal and sinusoidal egg curves $[7,10,8]$.

Fig 1 shows double egg curves eligible to be designed in different ways. Double egg curves shaped according to circles lie one within the other (Fig. 1a), the coverage of two small circles by the big one (Fig. 1b), coverage of small circle by two big circles (Fig. 1c). In this study, design and calculation of a double egg curve clothoid was carried out according to the model given in Fig 1a.

According to the three models given in Fig. 1, double-egg curve consists of 8 main points. Here, points $\mathrm{KA}_{1}$ and $\mathrm{KE}_{1}$ on a clothoid with parameters of $A_{1}$ and $R_{1}$, points $\mathrm{KE}_{1} \div \mathrm{KE}_{\mathrm{I} 11}$ on a circle with a radius of $R_{1}$, points $\mathrm{KE}_{\mathrm{I} 11}$ and $\mathrm{KE}_{\mathrm{i} 12}$ on a clothoid with parameters of $A_{\mathrm{EI} 1}$ and $R_{2}$ (first egg curve), points $\mathrm{KE}_{\mathrm{I} 12}$ and $\mathrm{KE}_{\mathrm{i} 21}$ on a circle with a radius of $R_{2}$, points $\mathrm{KE}_{\mathrm{i} 21}$ and $\mathrm{KE}_{\mathrm{i} 22}$ on a clothoid with parameters of $A_{\mathrm{EI} 2}$ and $R_{3}$ (second egg curve), points $\mathrm{KE}_{\mathrm{i} 22}$ and $\mathrm{KE}_{2}$ on a circle with a radius of $R_{3}$ and finally points $\mathrm{KE}_{2}$ and $\mathrm{KA}_{2}$ on clothoid with parameters of $A_{2}$ and $R_{3}$ are presented. These points can be described as the common point for the given clothoid and the circle as follows: point $\mathrm{KE}_{1}$, for $A_{1}$ clothoid and a circle with a radius of $R_{1}$; point $\mathrm{KE}_{\mathrm{I} 11}$, for $A_{\mathrm{E} \text { I } 1}$ clothoid and a circle with a radius of $R_{1}$; point $\mathrm{KE}_{\mathrm{I} 12}$, for $\mathrm{A}_{\mathrm{E} \text { i1 }}$ clothoid and a circle with a radius of $R_{2}$; point $\mathrm{KE}_{\mathrm{i} 21}$, for $A_{\mathrm{Ei} 2}$ clothoid and a circle with a radius of $R_{2}$; point $\mathrm{KE}_{\mathrm{i} 22}$, for $A_{\mathrm{Ei} 2}$ clothoid and a circle with a radius of $R_{3}$; point $\mathrm{KE}_{2}$, for $A_{2}$ clothoid and a circle with a radius of $R_{3}$. The tangent lines are in common at these points. One of the most important data obtained from the parameters of egg curves is the distances, which are shown in Fig. 2 as $D_{1}$ and $D_{2}$, between the big and small circles located at a closest distance to each other. These values are obtained from the map forming the basement of the project as graphically or from the numerical medium. $A_{\mathrm{E} \text {, }}$, a parameter of the egg curve, is calculated from Eq. (1) [11, 9].

$L_{\mathrm{EI}}=\frac{A_{\mathrm{EI}}^{2}}{R}, D=\frac{L_{\mathrm{EI}}^{2}}{24 \cdot R}, R=\frac{R_{1} \cdot R_{2}}{R_{1}-R_{2}}, A_{\mathrm{EI}}=\sqrt[4]{24 \cdot D \cdot R^{3}}$,

where, $R_{1}, R_{2}, D$ and $A_{\mathrm{Ei}}$ are defined as the radius of the big circle, radius of the small circle, the smallest distance between the arcs of big and small circles and the parameter of the egg curve, respectively. The lengths of clothoid segments (egg curve) are represented as:

$L_{\mathrm{EI} 1}=L_{\mathrm{KEI} 12}-L_{\mathrm{KE} 111} ; L_{\mathrm{Ei} 2}=L_{\mathrm{KEi} 22}-L_{\mathrm{KE} 121}$

\subsection{Basic calculations of double-egg curve}

In practice, in order to solve the turning problem, a study is carried out on a large-scale plan of the working area and required calculations are performed after determination of parameters belonging to rotation axis parts. The values of $T_{1}=\mathrm{S}_{2} \mathrm{KA}_{1}, T_{2}=\mathrm{S}_{2} \mathrm{KA}_{2}, A_{1}, R_{1}, R_{2}, R_{3}$, $A_{2}, D_{1}$ and $D_{2}$ were found following to the preliminary studies carried out in a plan undertaken in this study. Then, by using $R_{1}, R_{2}, D_{1}$ and formulas given in Eq. (1) the value of $A_{\text {EII }}$ and similarly, by using $R_{2}, R_{3}$ and $D_{2}$ the value of $A_{\text {Ei2 }}$ parameter was calculated, see Fig. 2. In order to calculate the 8 main points of the double egg curve by the data obtained, the coordinates of centre of circles $\mathrm{M}_{1}, \mathrm{M}_{2}$ and $\mathrm{M}_{3}$, central angles of circular arc, aperture angles of tangent direction belonging to egg curve as well as intermediate and main tangent lengths are calculated.

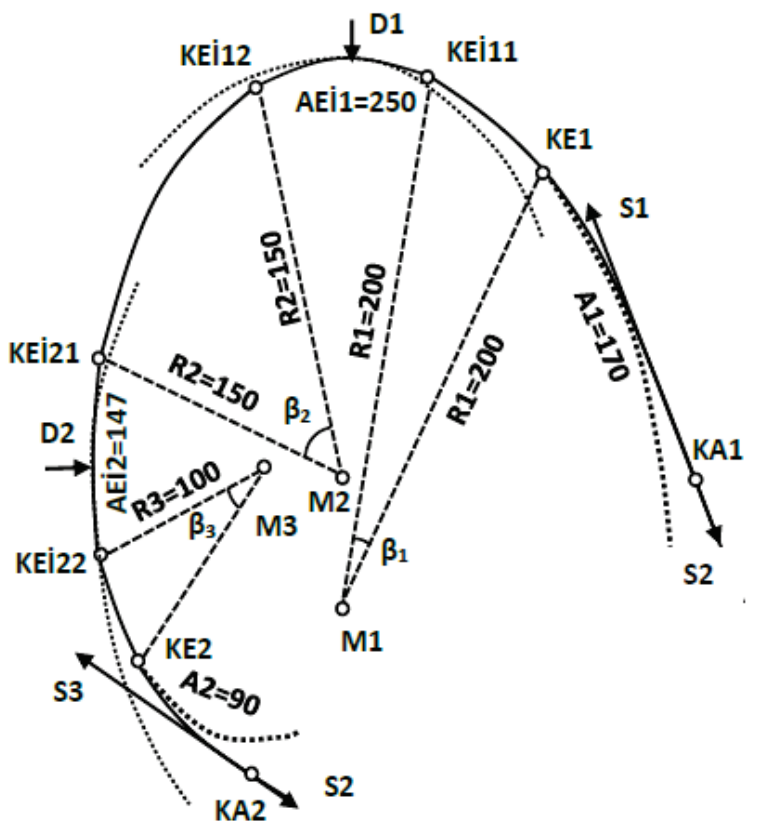

Figure 2 Double-egg curves formed by circles lie one within the other

\subsubsection{Coordinate calculations of the centre of circles}

Firstly, basic elements of all clothoids are calculated by using the clothoid parameters given in Fig. 2. These are; $L=$ length of a clothoid, $\tau=$ tangential angle, $X_{\mathrm{M}}=$ abscissa of a centre of a circle, $Y_{\mathrm{M}}=$ ordinate of a centre of a circle, $\mathrm{DR}=$ length of transition curve, $\mathrm{y}=$ ordinate of the end of the clothoid, $x=$ abscissa of the end of the clothoid, $T U=$ long tangent, $T K=$ short tangent. In order to separate the elements from each other, own index of each clothoid will be used. The coordinates of centre of circles, $\mathrm{M}_{1}$ and $\mathrm{M}_{3}$, are calculated by using lengths of tangents $T_{1}$ and $T_{2}$. The centre of circle, $\mathrm{M}_{1}$, and $\mathrm{KA}_{1}$ can be calculated by means of basic elements of a clothoid with the parameter values of $A_{1}$ and $R_{1}$ as follows: 
$y_{m 1}=y_{2}+\left(T_{1}+X M_{1}\right) \sin \left(S_{2} S_{1}\right)+\left(R_{1}+D R_{1}\right) \cdot \sin \left(\left(S_{2} S_{1}\right)-100\right)$

$x_{m 1}=x_{2}+\left(T_{1}+X M_{1}\right) \cos \left(S_{2} S_{1}\right)+\left(R_{1}+D R_{1}\right) \cdot \cos \left(\left(S_{2} S_{1}\right)-100\right)$

$y_{K A 1}=y_{2}+T_{1} \cdot \sin \left(S_{2} S_{1}\right) x_{K A 1}=x_{2}+T_{1} \cdot \cos \left(S_{2} S_{1}\right)$

In the same manner, the centre of circle, $\mathrm{M}_{3}$, and $\mathrm{KA}_{2}$ can be calculated by means of basic elements of a clothoid with the parameter values of $A_{2}$ and $R_{3}$ as follows:

$$
\begin{aligned}
& y_{m 3}=y_{2}+\left(T_{2}+X M_{3}\right) \sin \left(S_{2} S_{3}\right)+\left(R_{3}+D R_{3}\right) \cdot \sin \left(\left(S_{2} S_{3}\right)+100\right) \\
& x_{m 3}=x_{2}+\left(T_{2}+X M_{3}\right) \cos \left(S_{2} S_{3}\right)+\left(R_{3}+D R_{3}\right) \cdot \cos \left(\left(S_{2} S_{3}\right)+100\right) \\
& y_{K A 2}=y_{2}+T_{2} \cdot \sin \left(S_{2} S_{3}\right) \\
& x_{K A 2}=x_{2}+T_{2} \cdot \cos \left(S_{2} S_{3}\right)
\end{aligned}
$$

\subsubsection{Calculation of the distance between the centres}

The values of $T_{\mathrm{UEI} 11}, T_{\mathrm{KEI} 11}, X_{\mathrm{MEI} 11}, D R_{\mathrm{EI} 11}, L_{\mathrm{EI} 11}, \tau_{\mathrm{EI} 11}$, $x_{\mathrm{E} 111}$ and $y_{\mathrm{E} \dot{1} 11}$ are calculated by using $A_{\mathrm{EI} 1}$ and $R_{1}$, while those of $T_{\mathrm{UEI} 12}, T_{\mathrm{KEI} 12}, X_{\mathrm{MEI} 12}, D R_{\mathrm{EI} 12}, L_{\mathrm{EI} 12}, \tau_{\mathrm{EI} 12}, x_{\mathrm{EI} 12}$ and $y_{\mathrm{EI} 12}$ are found by using $A_{\mathrm{EI} 1}$ and $R_{2}$. In this way, basic clothoid elements are calculated according to radius values of $R_{1}$ and $R_{2}$ belonging to the first egg curve.

When the basic elements in Fig. 4 are considered, the distance $M_{1} M_{2}$ is calculated from Eq. (4).

$$
M_{1} M_{2}=\sqrt{\left(X_{\mathrm{MEI} 12}-X_{\mathrm{MEI} 11}\right)^{2}+\left(R_{1}+D R_{\mathrm{EI} 11}-R_{2}-D R_{\mathrm{EI} 12}\right)^{2}} .
$$

In calculation of the basic elements of the clothoid belonging to the second egg curve, the values of $T U_{\mathrm{Ei} 21}$, $T K_{\mathrm{Ei} 21}, X M_{\mathrm{Ei} 21}, D R_{\mathrm{Ei} 21}, L_{\mathrm{Ei} 21}, \tau_{\mathrm{Ei} 21}, x_{\mathrm{E} i 21}$ and $y_{\mathrm{Ei} 21}$ are found by using $A_{\mathrm{Ei} 2}$ and $R_{2}$, while those of $T U_{\mathrm{EI} 22}, T K_{\mathrm{EI} 22}$, $X M_{\mathrm{Ei} 22}, D R_{\mathrm{Ei} 22}, L_{\mathrm{E} i 22}, \tau_{\mathrm{Ei} 22}, x_{\mathrm{Ei} 22}, y_{\mathrm{E} i 22}$ are calculated by using $A_{\mathrm{Ei} 2}$ and $R_{3}$. Similarly, the distance $\mathrm{M}_{3} \mathrm{M}_{2}$ is calculated.

$$
M_{3} M_{2}=\sqrt{\left(X_{\mathrm{MEI} 22}-X_{\mathrm{MEI} 21}\right)^{2}+\left(R_{2}+D R_{\mathrm{EI} 21}-R_{3}-D R_{\mathrm{EI} 22}\right)^{2}} .
$$

\subsubsection{Coordinate calculations of the center of circle M2}

The coordinates of point $\mathrm{M}_{2}$ are found by using the $\mathrm{M}_{1} \mathrm{M}_{2} \mathrm{M}_{3}$ triangle given in Fig. 3. Since the coordinates of $\mathrm{M}_{1}$ and $\mathrm{M}_{3}$ points as well as the $M_{1} M_{2}$ and $M_{2} M_{3}$ distances were calculated, three edges of the triangle are known.

$$
\begin{aligned}
& \left(M_{1} M_{3}\right)=\arctan \frac{y_{3}-y_{1}}{x_{3}-x_{1}} ;\left(M_{1} M_{3}+50\right)=\arctan \frac{\left(x_{3}+y_{3}\right)-\left(x_{1}+y_{1}\right)}{\left(x_{3}-y_{3}\right)-\left(x_{1}-y_{1}\right)}(6) \\
& M_{1} M_{3}=\frac{y_{3}-y_{1}}{\sin \left(M_{1} M_{3}\right)}=\frac{x_{3}-x_{1}}{\cos \left(M_{1} M_{3}\right)} \\
& \alpha_{1}=\arccos \left(\frac{S_{2}^{2}+S_{3}^{2}-S_{1}^{2}}{2 \cdot S_{2} S_{3}}\right), \alpha_{2}=\arccos \left(\frac{S_{1}^{2}+S_{3}^{2}-S_{2}^{2}}{2 \cdot S_{1} S_{3}}\right) \\
& \alpha_{3}=\arccos \left(\frac{S_{1}^{2}+S_{2}^{2}-S_{3}^{2}}{2 \cdot S_{1} S_{2}}\right) \\
& \text { Control: } \alpha_{1}+\alpha_{2}+\alpha_{3}=200 \\
& \left(M_{1} M_{2}\right)=\left(M_{1} M_{3}\right)+\alpha_{1} ; y_{m 2}= \\
& y_{m 1}+S_{3} \cdot \sin \left(M_{1} M_{2}\right) ; x_{m 2}=x_{m 1}+S_{3} \cdot \cos \left(M_{1} M_{2}\right)
\end{aligned}
$$

Control: $\left(M_{3} M_{2}\right)=\left(M_{3} M_{1}\right)-\alpha_{3}$;

$$
y_{m 2}=y_{m 3}+S_{1} \cdot \sin \left(M_{3} M_{2}\right) ; x_{m 2}=x_{m 3}+S_{1} \cdot \cos \left(M_{3} M_{2}\right)(
$$

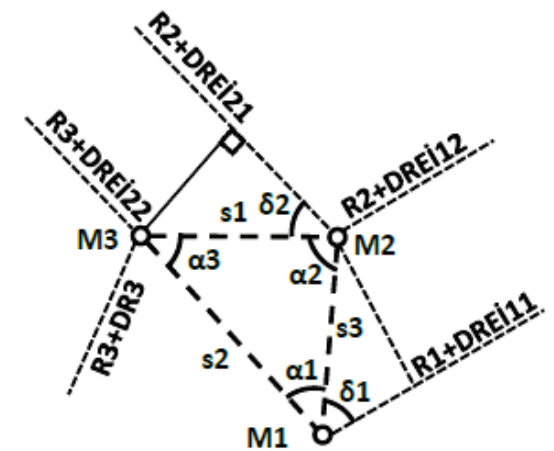

Figure 3 Auxiliary angles for egg curve tangents

\subsubsection{Determination of tangent directions belonging to egg curves}

In order to calculate the central angles of circles $\mathrm{M}_{1}$, $\mathrm{M}_{2}$ and $\mathrm{M}_{3}$ seen in Fig. 2 and visualize the points on the egg curve in a computer, aperture angles $\left(\alpha_{\mathrm{ei} 1}, \alpha_{\mathrm{e} i 2}\right)$ of tangent directions and tail coordinates should be calculated through the use of angles $\delta_{1}$ and $\delta_{2}$ (11) by considering Figs. 3 and 4.

$$
\begin{aligned}
& \tan \delta_{1}=\frac{X_{\mathrm{MEI} 12}-X_{\mathrm{MEI} 11}}{\left(R_{1}+D R_{\mathrm{EI} 11}-R_{2}-D R_{\mathrm{EI} 12}\right)}, \\
& \tan \delta_{2}=\frac{X_{\mathrm{MEI} 22}-X_{\mathrm{MEI} 21}}{\left(R_{2}+D R_{\mathrm{EI} 21}-R_{3}-D R_{\mathrm{EI} 22}\right)} .
\end{aligned}
$$

The aperture angles of tangent directions belonging to the first and second egg curves are found through the use of Eq. (12) by considering Fig. 4.

$\alpha_{\mathrm{ei} 1}=\left(M_{1} M_{2}\right)+\delta_{1}-100 ; \alpha_{\mathrm{ei} 2}=\left(M_{2} M_{3}\right)+\delta_{2}-100$.

Calculation of end points of tangent directions which are assumed to be $\mathrm{Q}_{1}$ and $\mathrm{Q}_{2}$ for the first direction and $\mathrm{Q}_{3}$ and $\mathrm{Q}_{4}$ for the second one is carried out by the help of related main clothoid elements according to the relation (13).

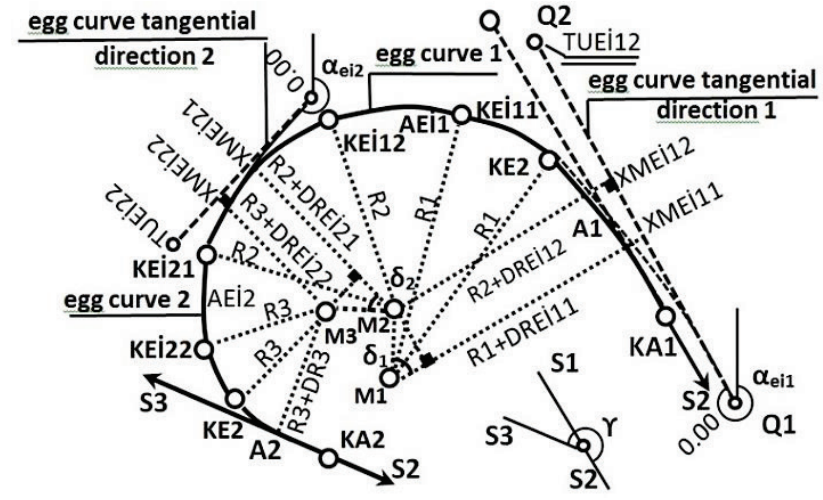

Figure 4 Tangent directions belonging to egg curves $\left(\alpha_{\mathrm{ei} 1}, \alpha_{\mathrm{ei} 2}\right)$

$$
\begin{aligned}
& y_{Q_{1}}=y_{m 1}+\left(R_{1}+\Delta R_{\mathrm{EI} 11}\right) \cdot \sin \left(\left(M_{1} M_{2}\right)+\delta_{1}\right)+X_{\mathrm{ME} \dot{1} 11} \cdot \sin \left(\alpha_{\mathrm{eil}} \pm 200\right) \\
& x_{Q_{1}}=x_{m 1}+\left(R_{1}+\Delta R_{\mathrm{EI} 11}\right) \cdot \cos \left(\left(M_{1} M_{2}\right)+\delta_{1}\right)+X_{\mathrm{ME} \dot{1} 11} \cdot \cos \left(\alpha_{\mathrm{eil}} \pm 200\right) \\
& y_{Q_{2}}=y_{Q_{1}}+T U_{\mathrm{EI} 12} \cdot \sin \alpha_{\mathrm{eil}}, x_{Q_{2}}=x_{Q_{1}}+T U_{\mathrm{EI} 12} \cdot \cos \alpha_{\mathrm{eil}}
\end{aligned}
$$


$y_{Q_{3}}=y_{m 2}+\left(R_{2}+D R_{\mathrm{Ei} 21}\right) \cdot \sin \left(\left(M_{2} M_{3}\right)+\delta_{2}\right)+X_{\mathrm{MEi} 21} \cdot \sin \left(\alpha_{\mathrm{ei} 2} \pm 200\right)$

$x_{Q_{3}}=x_{m 2}+\left(R_{2}+\Delta R_{\mathrm{EI} 21}\right) \cdot \cos \left(\left(M_{2} M_{3}\right)+\delta_{2}\right)+X_{\mathrm{MEI} 21} \cdot \cos \left(\alpha_{\mathrm{ei} 2} \pm 200\right)$

$y_{Q_{4}}=y_{Q_{3}}+T U_{\mathrm{EI} 22} \cdot \sin \alpha_{\mathrm{ei} 2}, x_{Q_{4}}=x_{Q_{3}}+T U_{\mathrm{EI} 22} \cdot \cos \alpha_{\mathrm{ei} 2}(13)$

\subsubsection{Calculation of central angles of circular arc}

When a vehicle coming from point $\mathrm{KA}_{2}$ reaches point $\mathrm{KA}_{1}$, it turns by the amount of deflection angle $\gamma$, which can be obtained by measurement of the angle carried out at point of intersection $\mathrm{S}_{2}$, see Fig. 4. However, sometimes, the angle can be found from indirect ways in cases where point $\mathrm{S}_{2}$ is not attainable. If the coordinates of points of intersection are known, the angle of $\gamma$ is calculated. The central angle $\beta_{1}$ is found from the following relations by considering Fig. 5 .

$\gamma_{1}=\left(S_{2} S_{1}\right)-\left(\alpha_{\mathrm{eil}}-\tau_{\mathrm{E} \dot{1} 12}\right)$

$\tau_{\mathrm{EI} 1}=\tau_{\mathrm{EI} 12}-\tau_{\mathrm{EI} 11}$

$\beta_{1}=\gamma_{1}-\left(\tau_{1}+\tau_{\mathrm{EI} 1}\right)$

Similarly, central angle $\beta_{3}$ is calculated from the following equations according to Fig. 6 .

$$
\begin{aligned}
& \gamma_{2}=\left(\alpha_{\mathrm{ei} 2}-\tau_{\mathrm{EI} 21}\right) \pm 200-\left(S_{2} S_{3}\right), \\
& \beta_{3}=\gamma_{2}-\left(\tau_{2}+\tau_{\mathrm{E} \dot{I} 2}\right) ; \tau_{\mathrm{EI} 2}=\tau_{\mathrm{EI} 22}-\tau_{\mathrm{EI} 21} .
\end{aligned}
$$

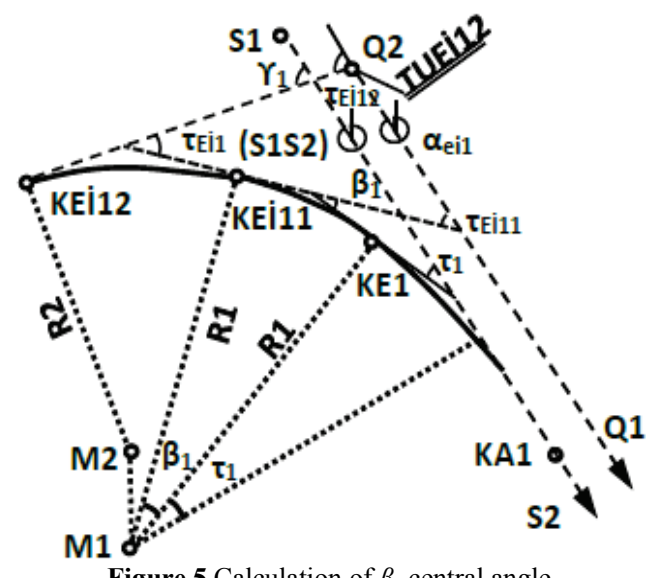

Figure 5 Calculation of $\beta_{1}$ central angle

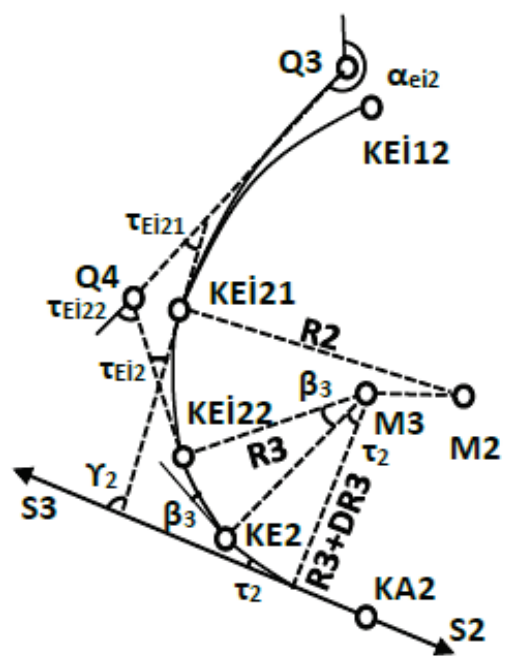

Figure 6 Calculation of $\beta_{3}$ central angle

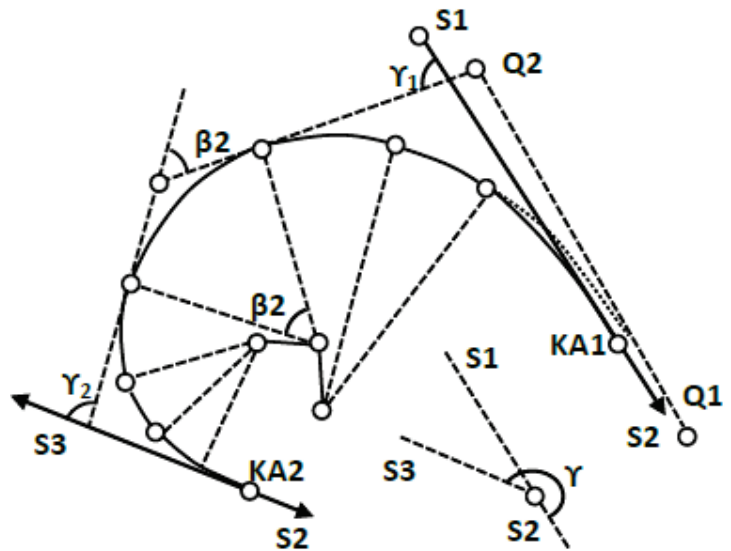

Figure 7 Calculation of $\beta_{2}$ angle

In the same manner, angle $\beta_{2}$ is obtained according to Fig. 7 as follows:

$\beta_{2}=\gamma-\left(\gamma_{1}+\gamma_{2}\right)$

Control:

$\gamma=\left(S_{1} S_{2}\right)-\left(S_{2} S_{3}\right)=\tau_{1}+\beta_{1}+\tau_{\mathrm{E} \dot{1} 1}+\beta_{2}+\tau_{\mathrm{E} \dot{2} 2}+\beta_{3}+\tau_{2}$

\subsubsection{Calculation of lengths of main and intermediate tangents}

The lengths of tangents given as $k_{4}=T_{\mathrm{UEI} 1}$ and $k_{5}=$ $T_{\text {KEI1 }}$ belonging to the egg curve clothoid with a parameter of $A_{\text {EI } 1}$ and radii of $R_{1}$ and $\mathrm{R}_{2}$ can be calculated by using the sine law considering Fig. 8. Here, the values of $k_{1}, k_{2}$ and $k_{3}$ are already known as basic clothoid elements $\left(k_{1}=\right.$ $\left.T_{\mathrm{UEI} 12}-T_{\mathrm{UEI} 11} ; k_{2}=T_{\mathrm{KEI} 12} ; k_{3}=T_{\mathrm{KEI} 11}\right)$.

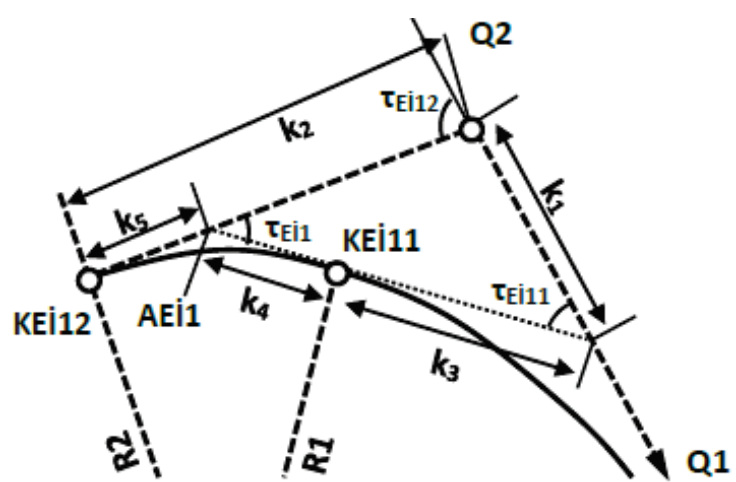

Figure 8 Calculations of lengths of tangents belonging to the egg curve

$k_{4}=T U_{\mathrm{EI} 1}=\sin \tau_{\mathrm{EI} 12} \cdot \frac{k_{1}}{\sin \tau_{\mathrm{E} \dot{1} 1}}-k_{3}$,
$k_{5}=T K_{\mathrm{EI} 1}=k_{2}-\sin \tau_{\mathrm{EI} 11} \cdot \frac{k_{1}}{\sin \tau_{\mathrm{EI} 1}}$.

Since there are two egg curves, lengths of tangents $T U_{\mathrm{E} i 2}$ and $T K_{\mathrm{EI} 2}$ of the second egg curve are found in the same way. Lengths of tangents belonging to the circular arcs are calculated according to the Eq. (22).

$t_{i}=R_{i} \cdot \tan \frac{\beta_{i}}{2}$ 


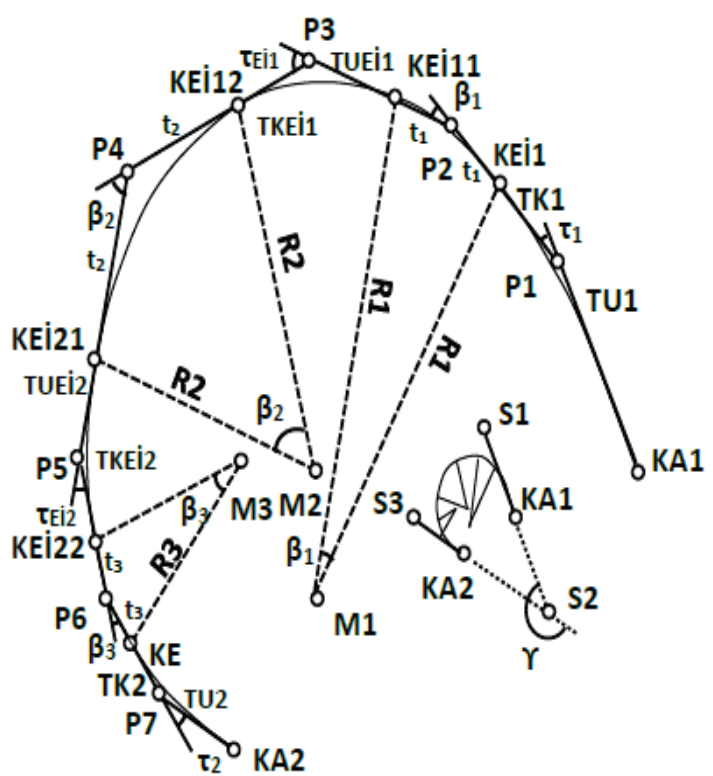

Figure 9 Lengths and angles of tangents

Due to the presence of 3 circular arcs in the double egg curves, 3 tangent lengths are calculated. Fig. 9 shows the tangent lengths and angles belonging to double egg curve line geometry. Whether the tangent lengths assumed in the beginning are obtained or not should be checked by measuring the main tangent lengths. Based on the circles with the biggest and the smallest radius, tangent lengths of the double egg curve are calculated. The tangent lengths $T_{1}$ and $T_{2}$ in terms of circle and clothoid parameters are calculated by considering Fig. 10 and assuming $\alpha$ as the deflection angle of tangent directions connecting the peaks $\mathrm{S}_{1}, \mathrm{~S}_{2}$ and $\mathrm{S}_{3}, R_{1}$ as the radius of the biggest circle, $D R_{1}$ as the easement curve length of clothoid with parameter $A_{1}, R_{3}$ as the minimum radius and $D R_{3}$ as the length of the easement curve of this clothoid.

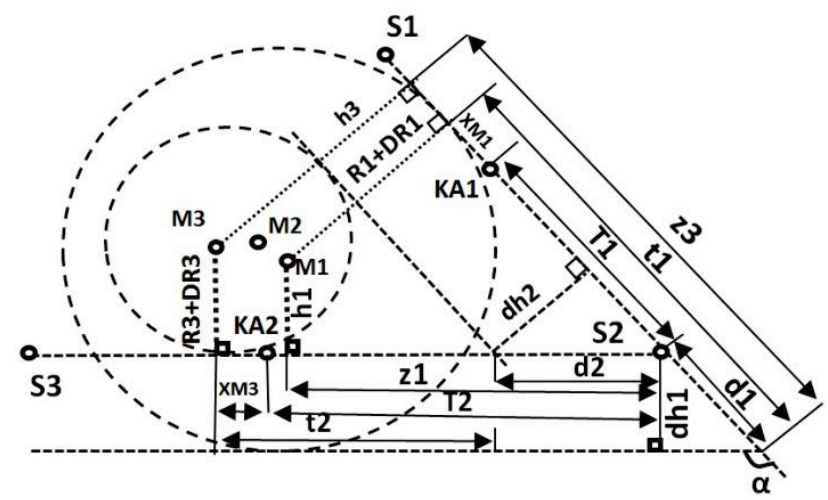

Figure10 Calculations of tangents lengths $T_{1}$ and $T_{2}$

$T_{1}=t_{1}-X M_{1}-d_{1}=$

$=\left(R_{1}+D R_{1}\right) \cdot \tan \frac{\alpha}{2}-X M_{1}-\frac{\left(R_{1}+D R_{1}\right)-h_{1}}{\sin \alpha}$,

$T_{2}=t_{2}-X M_{3}+d_{2}=$

$=\left(R_{3}+D R_{3}\right) \cdot \tan \frac{\alpha}{2}-X M_{3}+\frac{h_{3}-\left(R_{3}+D R_{3}\right)}{\sin \alpha}$.

The values of $h_{1}$ and $h_{3}$ given in the above equations are found through transformation calculation as follows. Assume that the starting point of tangent direction is $\mathrm{S}_{2}$ :
A, end point of that is $\mathrm{S}_{3}: \mathrm{B}$ and $\mathrm{S}_{2} \mathrm{~S}_{3}$ distance is $\mathrm{s}$, then, $\mathrm{h}_{1}$ height of point $\mathrm{M}_{1}$ is obtained by the following equations $(25,26)$.

$$
\begin{aligned}
& o=-\frac{\left(y_{b}-y_{a}\right)}{s}, a=\frac{\left(x_{b}-x_{a}\right)}{s}, \\
& s=\sqrt{\left(y_{b}-y_{a}\right)^{2}+\left(x_{b}-x_{a}\right)^{2}} . \\
& h_{1}=o \cdot\left(x_{1}-x_{a}\right)+a \cdot\left(y_{1}-y_{a}\right) .
\end{aligned}
$$

Similarly, $h_{3}$ height of central point $\mathrm{M}_{3}$ is also obtained. Calculations of $D$ intervals are performed according to Eq. (27).

$$
D_{1}=R_{1}-R_{2}-M_{1} M_{2}, D_{2}=R_{2}-R_{3}-M_{2} M_{3} .
$$

\subsubsection{Calculation of the coordinates of the main points}

According to tangents of polygon given in Fig. 9, calculation of the coordinates of the main points, from tangential point $\mathrm{KA}_{1}$ to $\mathrm{KA}_{2}$, should be conducted. As the coordinates of the $\mathrm{KA}_{1}$ and $\mathrm{KA}_{2}$ points are known, calculation of coordinates is performed by means of connecting traverse. Angles with common tangents are taken as $200^{\circ}$. After main point, calculation of intermediate points is performed. After determination of the coordinates of the main points, local coordinates of the intermediate points are calculated according to the length of the intermediate distance. Then, they are converted to national coordinate system. Intermediate points of which national coordinates are determined are marked on the territory by using one of the different application methods. This application is performed with the help of constant points which are close to the line [12 $\div 15]$.

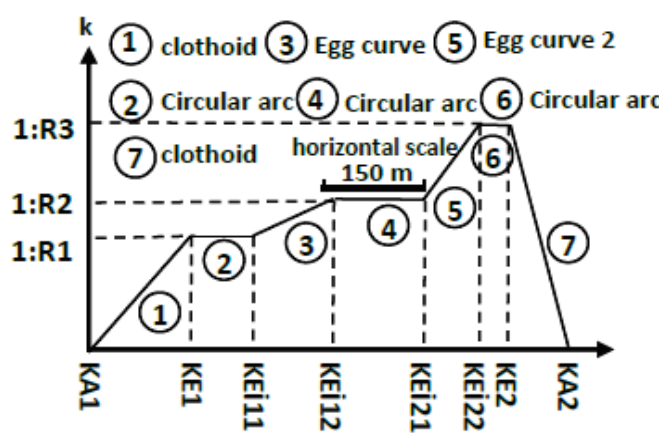

Figure 11 Curvature graph of the double-egg curve line

\subsection{Curvature diagram of the double-egg curve}

Curvature graph of the double-egg curve can be seen in Fig. 11. The curvature of each arc circle equals the inverse of its own radius and constant along the arc. The curvature at any point of clothoid and egg curve is calculated according to Eq. (28).

$k_{i}=k_{b} \pm \frac{1}{R_{i}}=k_{b} \pm \frac{1}{A^{2}} d s, \quad k_{\mathrm{b}}=\frac{1}{R}$,

where, $k_{i}=$ curvature at point $i$ and $k_{b}=$ the initial curvature of the axis. If the starting point is on the line, 
then $k_{b}=0 ; R_{i}=$ the radius at $i ; A=$ klothoid parameter; $d s$ $=$ the distance between point $i$ and the starting point of the corresponding pieces of axis in clothoid parameter.

\section{Application and results}

Inputs: According to the preliminary studies, it was found from Eq. (1) that $A_{\mathrm{EI} 1}=250$ and $A_{\mathrm{Ei} 2}=147$ for $R_{1}=200, \quad R_{2}=150, \quad D_{1}=0,749$ and $R_{2}=150, \quad R_{3}=100$, $D_{2}=0,717$, respectively. The other data are $T_{1}=348,347$, $T_{2}=486,303, A_{1}=170, A_{2}=90$ as well as the coordinates of the points $\mathrm{S}_{1}, \mathrm{~S}_{2}$ and $\mathrm{S}_{3}$.

Required Data: a) the coordinates of $\mathrm{M}_{1}, \mathrm{M}_{2}$ and $\mathrm{M}_{3}$ centres of circles $b$ ) The coordinates of the main points $c$ ) The central angle of arc of d) The length of each part e) re-calculation of $D_{1}$ and $D_{2}$ to make a check. Coordinates of the main and auxiliary points of egg curve (Fig. 9) are calculated by using explanations, equations as well as the input data given in the study and given in Tab. 1 .

Table 1 The coordinates of the double-egg curve Summary of the coordinates

\begin{tabular}{|c|c|c|c|c|c|}
\hline \multicolumn{6}{|c|}{ Summary of the coordinates } \\
\hline $\mathrm{N} . \mathrm{N}$. & $y$ & $x$ & $\mathrm{~N} . \mathrm{N}$. & $y$ & $x$ \\
\hline $\mathrm{S}_{1}$ & $\mathbf{6 8 1 0 , 6 8 2}$ & $\mathbf{4 4 1 1 , 9 9 5}$ & $\mathrm{P}_{1}$ & 6895,784 & 4277,093 \\
\hline $\mathrm{S}_{2}$ & $\mathbf{7 1 3 3 , 3 9 3}$ & $\mathbf{3 9 0 0 , 4 2 9}$ & $\mathrm{K}_{\mathrm{E} 1}$ & 6856,861 & 4306,484 \\
\hline $\mathrm{S}_{3}$ & $\mathbf{6 4 6 9 , 0 9 3}$ & $\mathbf{4 1 7 8 , 2 8 8}$ & $\mathrm{P} 2$ & 6825,826 & 4329,919 \\
\hline $\mathrm{M}_{1}$ & $6736,338 \sqrt{ }$ & $4146,877 \sqrt{ }$ & $\mathrm{K}_{\mathrm{EI} 11}$ & 6788,271 & 4340,017 \\
\hline $\mathrm{KA}_{1}$ & $6947,536 \sqrt{ }$ & $4195,052 \sqrt{ }$ & $\mathrm{P} 3$ & 6733,966 & 4354,620 \\
\hline $\mathrm{M}_{3}$ & $6687,231 \sqrt{ }$ & $4198,388 \sqrt{ }$ & $\mathrm{K}_{\mathrm{EI} 12}$ & 6685,739 & 4337,290 \\
\hline $\mathrm{KA}_{2}$ & $6684,754 \sqrt{ }$ & $4088,083 \sqrt{ }$ & $\mathrm{P}_{4}$ & 6614,015 & 4311,518 \\
\hline $\mathrm{M}_{2}$ & $6736,461 \sqrt{ }$ & $4196,128 \sqrt{ }$ & $\mathrm{K}_{\mathrm{EI} 21}$ & 6592,540 & 4238,393 \\
\hline $\mathrm{Q}_{1}$ & $7003,418 \sqrt{ }$ & $4125,096 \sqrt{ }$ & $\mathrm{P}_{5}$ & 6581,398 & 4200,451 \\
\hline $\mathrm{Q}_{2}$ & $6846,395 \sqrt{ }$ & $4395,020 \sqrt{ }$ & $\mathrm{K}_{\mathrm{EI} 22}$ & 6592,139 & 4167,443 \\
\hline $\mathrm{Q}_{3}$ & $6673,765 \sqrt{ }$ & $4355,586 \sqrt{ }$ & $\mathrm{P}_{6}$ & 6599,303 & 4145,427 \\
\hline $\mathrm{Q}_{4}$ & $6567,032 \sqrt{ }$ & $4244,594 \sqrt{ }$ & $\mathrm{K}_{\mathrm{E} 3}$ & 6615,414 & 4128,800 \\
\hline $\mathrm{KA}_{2}$ & $6684,754 \sqrt{ }$ & $4088,083 \sqrt{ }$ & $\mathrm{P}_{7}$ & 6634,501 & 4109,101 \\
\hline
\end{tabular}

Quantities necessary for the calculation of the coordinates of the main points on the double-egg curve line are given in Tab. 2.

Table 2 Fundamental quantities of the double-egg curve

Projection calculations of $\mathrm{M}_{3}$ and $\mathrm{M}_{1}$ central points on tangential lines

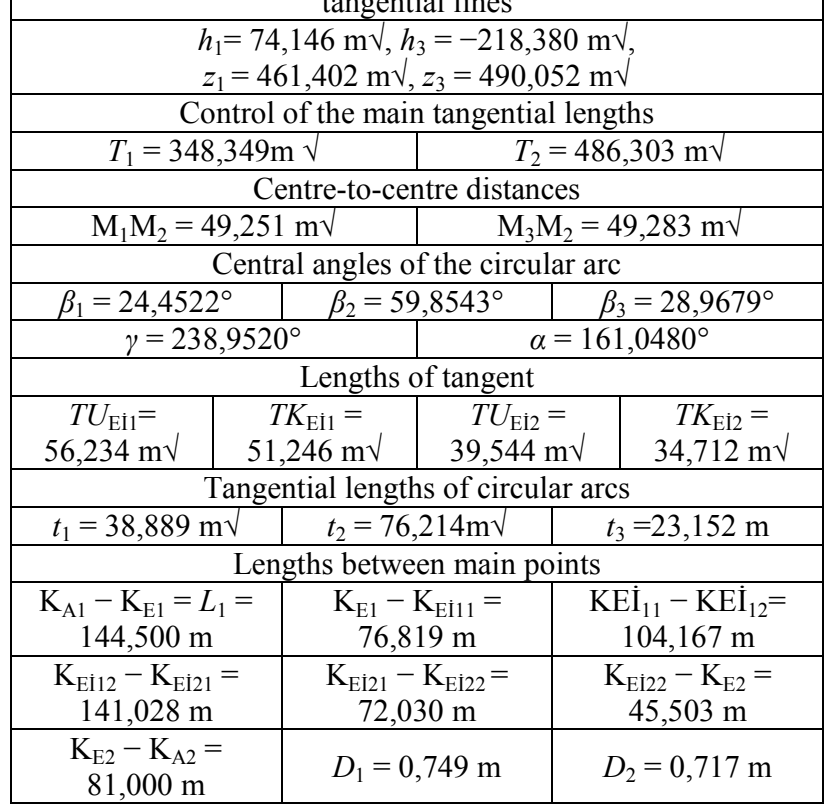

\section{Conclusions}

For safer and more comfortable link roads, local and economic conditions are important factors in determination of the line geometry. Within this scope, the application of double-egg curve has the ability to suit both topographic and economic conditions at the highest level. This is because a double-egg curve is composed of successive lining of seven different axes of pieces having different parameters.

By this way, a vehicle is not subjected to a sudden change in curvature when it passes from one axis to another but instead it changes linearly or keeps constant (Fig. 11). As a result of this, the effect of centrifugal force is minimized and a safe transportation is attained.

In order to achieve this, design and application of the double-egg curve examined were performed step-by-step and calculations were explained by using equations and figures. For users, design and calculation of double-egg curve with these properties are beneficial in terms of their applicability and control. This study may guide practitioners, student and those who are dealing with the issue with the content of paper presented here to design, to calculate and to layout of two eggs curves.

\section{References}

[1] Roder, H.; Hembel, W. Ingenieurvermesung Grunddaufgaben der Absteckung und Bogenabsteckung; Band 1, 1. Auflage, Ingenieurschule für Geodaesie und Kartographie Dresden Deutschland, 1963.

[2] Osterloh, H. Strassenplnung mit Klothoiden, dritte, erweiterte Auflage. Bauverlag GMBH, Weisbaden, Berlin, Deutschland, 1991.

[3] Pietzch, W. Strassenplanung; 3. Neubearbeitete und erweiterte Auflage. Werner Verlag, Duesseldorf, Deutschland, 1979.

[4] Müller, G. Ingeniergeodaesie - Verkehrsbau - Grundlagen. VEB Verlag für Bauwesen, Berlin, Deutschland, 1984.

[5] Müller, G. Ingeniergeodaesie - Verkehrsbau - Strassenbau. VEB Verlag für Bauwesen, Berlin, Deutschland, 1988

[6] Osterloh, H. Strassenplnung mit Klothoiden und Scleppkurven Einrechnung von Trasse und Gradiente. Bauverlag GMBH, Weisbaden, 1991.

[7] Megyeri, J. Eissenbahn-Bewegungsgeometrie. Akademia Kiado, Jeno, 1993.

[8] Baykal, O.; Tarı, E.; Coşkun, Z. Mühendislik Ölçmeleri -I Kara Demiryollarında Geçgi Geometrisi Tasarımı Veaplikasyonu, Cilt - II Sayısal Örnekler. Birsen Yayınevi, İstanbul, 2009.

[9] Koç, İ. Yumurta Eğrisi Tasarımı ve Hesabı, 5. Ulusal Mühendislik Ölçmeleri Sempozyumu 20-22 Ekim 2010, ZKÜ - Zonguldak, pp. 537-546.

[10] Baykal, O.; Tarı, E.; Coşkun,Z. Mühendislik Ölçmeleri -I Kara Demiryollarında Geçki Geometrisi Tasarımı Ve aplikasyonu, Cilt - I Metinler. Birsen Yayınevi, İstanbul, 2009.

[11] Hennecke, F.; Müler, G.; Werner, H. Handbuch Ingenieurvermessung Ingenieurvermessung Verkehrsbau-Trassen, VEB Verlag für Bauwesen, Berlin, 1990.

[12] Koç, İ. Die Berechnung der Absteckdaten von Strassenachsen mit dem Handcomputer. // Journalof Yildiz Technical University, 1999, pp. 51-65.

[13] Koç, İ. Ölçme Bilgisinde Bazı Konular ve Sayısal Uygulamalar II, Gökhan Matbaas1, İstanbul, 1996.

[14] Koç, İ. Ölçme Bilgisi I, Gökhan Matbaası, İstanbul, 1998. 
[15] Koç, İ. Ölçme Bilgisinde Bazı Konular ve Sayısal Uygulamalar I, Gökhan Matbaası, İstanbul, 1995

[16] Zhang K.; Tan Y.; L1 X.; The Coordinate Inspection of the Egg Curve in Highway Survey. // Bulletın of Surveyıng and Mapping. 4(2004), pp 39-42.

[17]Pırt1 A.; Yücel, M. A.; The fourth degree parabola (Biquadratic parabola) as a transition curve. Tehnički vjesnikTechnical Gazette. 19, 1(2012), pp. 19-26.

\section{Authors' addresses}

İbrahim Koç, Dr

Yildiz Technical University,

Civil Engineering Faculty,

Geomatic Engineering, Istanbul, Turkey

Phone: +902123832991, Fax: +90 2123835274,

E-mail: ibkoc@yildiz.edu.tr

Kutalmış Gümüş, Dr

Niğde University,

Engineering Faculty,

Geomatic Engineering Department,

51245 Niğde, Turkey

Phone: +90 3882252226, Fax: +90 3882250112

E-mail: kgumus@nigde.edu.tr

Mahmut Oğuz Selbesoğlu, MSc

Yildiz Technical University,

Civil Engineering Faculty,

Geomatic Engineering, Istanbul, Turkey

Phone: +902123835310, Fax: +902123835274,

E-mail: oguzs@yildiz.edu.tr 